\title{
Distribution of Pontomesencephalic Cholinergic Neurons Projecting to Substantia Nigra Differs Significantly from Those Projecting to Ventral Tegmental Area
}

\author{
Scott A. Oakman, ${ }^{1}$ Patricia L. Faris,, ${ }^{2}$ Philip E. Kerr,, ${ }^{2}$ Constantino Cozzari, ${ }^{3}$ and Boyd K. Hartman ${ }^{2}$ \\ ${ }^{1}$ Graduate Program in Neuroscience and ${ }^{2}$ Division of Neuroscience Research, Department of Psychiatry, University \\ of Minnesota, Minneapolis, Minnesota 55455 and ${ }^{3}$ Institute of Cellular Biology, CNR, Rome, Italy
}

Locations of pontomesencephalic cholinergic projection neurons from the laterodorsal tegmental (LDTg) and pedunculopontine tegmental (PPTg) nuclei to midbrain dopaminergic nuclei were mapped. Stereotaxic microinjections of Fluoro-Gold- or rhodamine-labeled microspheres were made either to substantia nigra (SN) or ventral tegmental area (VTA) in rat. Choline acetyltransferase was visualized immunohistochemically. Labeled cells were digitally mapped at multiple levels of the nuclei using an interactive computer/microscope system.

$\mathrm{SN}$-projecting neurons were distributed predominately ipsilaterally in distinct regions of the PPTg: either at its rostral pole or caudally in an area ventromedial to the superior cerebellar peduncle. Few SN-projecting neurons were found in LDTg. VTA-projecting neurons were distributed bilaterally throughout the cholinergic group, primarily in the densest regions of the LDTg and caudal PPTg. Neurons were not strictly segregated into these patterns. Scattered cells belonging to either projection could be found throughout the cholinergic group on either side. Hierarchical log-linear analysis showed these differences in topographic distribution to be statistically significant. Subtraction of cell density images demonstrated well delineated regions of the cholinergic group where the projections were predominately either to SN or VTA. These data indicate a high degree of internal organization within the pontomesencephalic cholinergic group based on the location of efferent projections to SN or VTA. These findings support the concept that this cholinergic group is functionally organized in a manner which selectively innervates motor (SN) and limbic (VTA) dopaminergic nuclei.

[Key words: cholinergic, substantia nigra, ventral tegmental area, pontomesencephalic, pedunculopontine, laterodorsal tegmental, retrograde, pathway tracing, immunohistochemistry, hierarchical log linear]

Received Feb. 1, 1995; revised Apr. 20, 1995; accepted Apr. 25, 1995.

We thank Dr. Ross D. Crosby for contributing his statistical expertise to this project, and Joseph Howard and Randall Hofbauer for their contributions to related projects. This work was supported by NS12311 (B.K.H.), MH47189 (P.L.F.), and a National Science Foundation Graduate Fellowship to S.A.O. Publication number 121 from the Division of Neuroscience Research.

Correspondence should be addressed to Boyd K. Hartman, Division of Neuroscience Research, Box 392 UMIIC, University of Minncsota, Minncapolis, MN 55455.

Copyright $@ 1995$ Society for Neuroscience $\quad 0270-6474 / 95 / 155859-11 \$ 05.00 / 0$
Tract-tracing studies have documented that the pontomesencephalic cholinergic complex, located within the laterodorsal tegmental (LDTg) and pedunculopontine tegmental (PPTg) nuclei of the brainstem, innervates a variety of structures throughout the brain, in particular contributing a substantial cholinergic innervation to the thalamus (Wooll and Butcher, 1986, 1989; Rye et al., 1987; Hallanger and Wainer, 1988; Lee et al., 1988). Evidence from studies combining tract-tracing techniques with ChAT immunohistochemistry suggests that these efferents are distributed within the cholinergic group according to functional characteristics of their targets. For example, injections of retrograde tracers in thalamic nuclei and forebrain targets associated with the limbic system will preferentially label neurons in LDTg, whereas extrapyramidal regions and thalamic nuclei associated with sensory or motor functions are more likely to receive afferents from neurons in the PPTg (Woolf and Butcher, 1986; Hallanger et al., 1987; Saxena and Hartman, 1989).

In addition to the forebrain structures discussed above, the major mesencephalic dopaminergic nuclei, the substantia nigra (SN) and ventral tegmental area (VTA), also receive cholinergic innervation from neurons in the LDTg and PPTg. Anatomical evidence at both the light and electron microscopic levels suggests that the $\mathrm{SN}$ receives a dense cholinergic innervation (Martinez-Murillo et al., 1989; Bolam et al., 1991), and cholinergic fibers and terminals are also observed in VTA of rat and ferret (Hartman et al., 1988; Henderson and Sherriff, 1991). Studies combining immunohistochemistry for choline acetyltransferase (ChAT) and various anterograde and retrograde tract-tracing methods have demonstrated that these fibers include efferents from cells in the LDTg and PPTg (Woolf and Butcher, 1985, 1986; Beninato and Spencer, 1987; Clarke et al., 1987; Gould et al., 1989).

The SN and VTA, while both containing dopaminergic projection neurons, are associated with divergent functions, the nigrostriatal projections subserving a motor function and the mesolimbic VTA projections innervating regions associated with motivation, reward, and arousal. The purpose of the present study was to compare the locations of cholinergic cells projecting to $\mathrm{SN}$ with those projecting to VTA in order to determine whether a similar scheme of functional organization is also found when examining projections of the cholinergic system to monoaminergic systems. In order to accomplish this, a novel statistically based approach for differentiating and comparing subpopulations of a cell group based on their projections and cell morphometrics was developed. Demonstrating that projections to two functionally divergent dopaminergic systems orig- 
inate from distinct subpopulations of the cholinergic complex will provide information about how projections from the cholinergic group to monoaminergic nuclei might be organized to regulate behavioral state.

\section{Materials and Methods}

Stereotaxic injections. Stereotaxic injections of fluorescent retrograde tracers were administered under halothane anesthesia to the VTA and SN pars compacta in young male Sprague-Dawley rats (Harlan, 200$350 \mathrm{gm}$ ). A $4 \%$ solution $(15-30 \mathrm{nl}$ ) of Fluoro-Gold (FG) (Fluorochrome Inc., Engelwood, $\mathrm{CO}$ ) or $50-300 \mathrm{nl}$ of stock suspension of rhodamineconjugated latex microspheres (RLM) (Lumafluor Inc., New City, NY) was pressure injected with a Hamilton syringe stereotaxically guided to the desired coordinates, based on the atlas of Paxinos and Watson (1986). Following 5-9 d survival, animals were anesthetized with a lethal dose of chloral hydrate and transcardially perfused with $0.16 \mathrm{M}$ $\mathrm{NaCl} \mathrm{pH} 7.4$ (0.05 M potassium phosphate solution) (PBS) for $2 \mathrm{~min}$, a $2 \%$ formaldehyde $/ 0.03 \%$ glutaraldehyde solution buffered to $\mathrm{pH} 6.5$ with $0.1 \mathrm{M}$ sodium acetate for $3 \mathrm{~min}$, and a $2 \%$ formaldehyde $/ 0.03 \%$ glutaraldehyde solution buffered to $\mathrm{pH} 8.5$ with $0.1 \mathrm{M}$ dibasic sodium phosphate for $20-30 \mathrm{~min}$. The brains were stereotaxically blocked at levels $1.5 \mathrm{~mm}$ posterior and $5.5 \mathrm{~mm}$ anterior to the interaural line and postfixed in $2 \%$ formaldehyde at $\mathrm{pH} 8.5$ for at least $2 \mathrm{~d}$. Serial coronal sections $(40 \mathrm{~mm})$ from the midbrain block were cut on a Lancer vibratome and collected sequentially into 24-well plastic tissue culture trays containing $0.1 \mathrm{M}$ potassium phosphate buffer ( $\mathrm{pH} 7.4$ ) with $0.02 \%$ sodium azide. The trays were wrapped in aluminum foil to minimize photodegradation of the Fluoro-Gold and stored at $4^{\circ}$

Verification of injection sites. One in four series of sections through each injection site were air dried onto gel-coated slides. The boundaries of the spread of the tracer were sketched onto previously prepared templates depicting the distribution of tyrosine hydroxylase in the SN and VTA. Brains with injections not largely confined to the target areas, or which included both VTA and SN, were excluded from further study.

Tissue selection. Sections from a total of 10 animals were selected at $500 \mu$ intervals through the pontomesencephalic cholinergic nucleus. Six animals had received tracer injections to the VTA and four had received injections to the SN. To minimize anatomical variability between brains due to differences in the anterior/posterior levels being sampled, a readily identifiable and reliable reference section was identified in each brain, and tissue sections to be analyzed were selected at set distances from this standard point. The reterence point selected was the first section, processing posterior to anterior, in which the superior colliculi were physically connected to the pontine tegmentum, corresponding approximately to interaural -0.3 of Paxinos and Watson.

Immunohistochemistry. Sections were processed for ChAT-fluorescence immunohistochemistry using a mouse monoclonal antihody of high specificity and affinity (mCAT mab17; $\mathrm{K}_{\mathrm{a}}=1.5 \times 10^{11}$ ) prepared in our lab (Cozzari et al., 1990), and a double-bridge visualization technique. Free-floating sections were prewashed overnight in a phosphatebuffered saline solution (PBS, $0.16 \mathrm{M} \mathrm{NaCl}$ in $0.02 \mathrm{M}$ potassium phosphate buffer, pH 7.2) containing $5 \%$ normal horse serum (NHS), $0.1 \%$ Triton $\mathrm{X}-100,1 \mathrm{mg} / \mathrm{ml}$ bovine serum albumin, and $0.02 \%$ sodium azide. Sections were then transferred to a solution containing the primary antibody at a final concentration of $4 \mathrm{mg} / \mathrm{ml}$ for a $4 \mathrm{hr}$ incubation at $20^{\circ}$ followed by an overnight incubation at $4^{\circ}$. Following brief washes in PBS containing $0.1 \%$ triton and $1.5 \%$ NHS, the secondary antibody (biotinylated horse anti-mouse at 1:200, Vector Labs, Burlingame, CA) was applied for $1 \mathrm{hr}$, washed, and the sections returned to the primary antibody solution for a second overnight incubation. Following a second application of the secondary antibody, the sections were incubated overnight in avidin-conjugated fluorophores (Vector) at $1: 1000$ in $0.1 \mathrm{M}$ potassium phosphate buffer. Texas red was used as the fluorophore for ChAT localization in FG-injected animals, and fluorescein isothiocyanate (FITC) to localize ChAT in the rhodamine latex bead-injected cases. Following a brief rinse in buffer, sections were mounted onto gel-coated slides. Sections from animals receiving injections of latex microspheres were aired dried and viewed without cover glass.

Although FG is an excellent retrograde tracer when used alone, cells faintly labeled with FG fade rapidly due to photodecomposition and are difficult to distinguish from neurons containing lipofuscin. In order to obtain maximum sensitivity and precision in visualizing and identifying FG transport, the sensitivity of the procedure was enhanced by immunohistochemical localization of FG (Chang et al., 1990). Sections from
FG-injected cases were processed for ChAT immunohistochemistry as above with the following exceptions: (1) An anti-FG primary antibody (Chemicon, Temecula, CA) was added with the anti-ChAT primary, and double-bridge immunohistochemistry for FG was performed simultaneously with the localization of ChAT. This procedure was applied to sections adjacent to those where $F G$ was visualized using its intrinsic fluorescence. (2) The rabbit anti FG antibody (FGAb) was visualized using a biotinylated goat anti-rabbit antibody (Vector) which was in turn visualized with avidin-conjugated Texas red. ChAT-positive cells in these same sections were visualized using nlab17, as above, and FITC-conjugated goat anti-mouse antibody (Tago, Camarillo, CA). These sections were mounted onto gel-coated slides and coverslipped with buffered glycerol. All sections were stored at $4^{\circ} \mathrm{C}$ until analysis was completed.

Sections through the injection sites were processed for verification of ChAT-positive fibers using the anti-ChAT mouse monoclonal, and visualized using an anti-mouse avidin-biotin complex (ABC Elite Kit; Vector) with nickel-cobalt intensification of 3,3-diaminobenzidine (DAB) to visualize the peroxidase reaction product. Sections again received an overnight prewash in phosphate-buffered saline (PBS) solution containing $5 \%$ normal horse serum, $0.1 \%$ Triton X-100, $1 \mathrm{mg} / \mathrm{ml}$ BSA, and $0.02 \%$ sodium azide, and were incubated in solution containing the primary antibody applied at a final concentration of $2 \mathrm{mg} / \mathrm{ml}$ for 4 hr at $20^{\circ} \mathrm{C}$ followed by overnight incubation at $4^{\circ} \mathrm{C}$. ABC kit procedures were used to visualize the bound ChAT antibody, and sections were mounted on gel-coated slides, dehydrated through a graded series of ethanols, and coverslipped in Permount out of xylene. Tyrosine hydroxylase-stained sections were similarly processed using a rabbit polyclonal antibody against bovine tyrosine hydroxylase (Berod et al., 1981; final concentration 1:8000 from whole serum) and anti-rabbit $\mathrm{ABC}$ method. For this antibody, the additional procedure of pre-extracting membrane lipids with a series of graded methanols beforc prewashing and incubating in primary was used to enhance antibody penetration in fixed tissue sections. (R. Hofbauer and P.L. Faris, unpublished observations).

Data acquisition and analysis. Matched stained sections taken at standard $500 \mu$ intervals through the pontomesencephalic cholinergic nuclei were examined on a Leitz Orthoplan II microscope equipped with $\mathrm{X}-\mathrm{Y}$ stage encoders. Leitz filter blocks used for epifluorescent microscopy were M2 (excitation filter $539-553 \mathrm{~nm}$ ) for visualization of Texas red or rhodamine and either $A(340-380 \mathrm{~nm})$ for visualization of $F G$, or L3 (450-490 nm) for visualization of FITC. The locations of labeled cells were digitally mapped with the assistance of a Leitz Microvid and 3-D data acquisition software running on an IBM-compatible platform (Bioquant, R\&M Biometrics, Nashville, TN). Each cell was entered into the system by tracing a cursor, superimposed within the microscopes field of view via the Microvid, around the outline of the cell by manipulating a mouse on a graphics pad. The cell outline was recorded digitally as a stream of points defined by $\mathrm{X}, \mathrm{Y}$, and $\mathrm{Z}$ coordinates, and a fourth integer corresponding to the user-defined cell type. This Bioquant data was transferred to a database program (4TH DIMENSION, ACIUS, Cupertino, CA) in which each cell was treated as a record in a relational data file. Customized routines written for the database were used to calculate XY coordinates of the cell center (center of gravity), cross-sectional area, and shape factor, an index of circularity $=4 \pi *$ Area/(Perimeter $)^{2}$. Additional routines allowed data from all sections to be aligned and rutated for subsequent comparisons on a single plane or axis. Alignment was achieved using the midpoint between the medial longitudinal fasciculi (mlf) as an orienting landmark in each mapped section. Orienting the data relative to this landmark preserved the columnar arrangement of the cholinergic nucleus through the midbrain and allowed clear discrimination of the PPTg and LDTg subdivisions when multiple levels were collapsed on the rostral-caudal axis. Routines were also written to calculate frequency distributions of single- and double-labeled cells along each axis, and density distributions of the cell groups on the XY plane. Data on cell locations, size, and shape was exported to SPSS (RELEASE 4.0 for Macintosh, SPSS Inc., Chicago, IL) for statistical analysis. Cell location and density data was exported to a commercially available graphics package (DELTAGRAPH, Delta Point, Inc., Monterey, CA) and plotted for each experimental group.

Distributions of cell locations were tested for statistical significance by using hierarchical log-linear analysis to compare frequency distributions along mediolateral (X), dorsoventral (Y), and rostrocaudal (Z) axes. These data were cross tabulated with variables representing group (SN or VTA injected) and cell type (single-labeled ChAT positive or 
double labeled for both ChAT and FG). Partial likelihood-ratio chi syuare $\left(L^{2}\right)$ statistics for efrects of each variable and all inleractions between variables were calculated (Fox, 1986; Norusis, 1990). Significant differences between distributions could then be determined from the value of the three-way (group by cell type by location) partial likelihood-ratio chi square.

This hierarchical approach is specifically required when comparing frequency distributions of data derived from different groups of animals. The approach permits the assignment of levels of statistical confidence to differences between subpopulations of such data over and above differences between the parent populations from which the subpopulations are drawn. Such differences may be due to slight differences in fixation, plane of section, or other variation between animals. For example, a two-dimensional model is sufficient to compare projecting to nonprojecting populations within the SN group, but a three-dimensional hierarchical model is required to compare the distributions of projecting neurons across both the SN and VTA groups since the distributions of cholinergic neurons in general differ between the two groups. Such differences may lead to false determinations of statistical significance where none exist.

To compare cell cross-sectional areas between the two groups, each group was rank ordered by area and divided into deciles. The area distributions of projecting cells were then expressed as the percentage of projecting cells found in each decile. These distributions across deciles could then be compared across groups using a standard $\chi^{2}$ test. Area data from SN and VTA cases were also compared to results from a single case in which a large $F G$ injection had been made in the anterior thalamus, thus examining possible similarities or differences between thalamic-projecting and SN/VTA-projecting cholinergic populations.

\section{Results}

Injection sites from 10 animals met criteria for inclusion in the study, six with VTA injections (four with FG, two with RLM as tracer) and four with $\mathrm{SN}$ injections (two FG, two RLM). The two more caudal FG injections into VTA included some spread of tracer into the interpeduncular nucleus. All SN injections involved the reticular portion of that nucleus to some extent (Fig. 1). In all cases, retrograde transport of tracer to the mesopontine tegmentum was observed. Areas in addition to the LDTg and PPTg which contained retrogradely labeled cells included the dorsal raphe, median raphe, parabrachial nuclei, and pontine reticular formation.

Immunohistochemical detection of ChAT in the mesopontine tegmentum was consistent with that noted in previous studies of the distribution of ChAT immunoreactivity. Large, intensely staining ChAT-positive cells were concentrated in the LDTg and PPTg. Tegmental areas in the vicinity of the superior cerebellar peduncle (SCP) also contained mumerous large ChAT-positive cells which, as a group, form a continuous arc connecting the two nuclei. In addition, the high affinity of the monoclonal antibody used allowed for the observation of a population of small, lightly staining cells in the parabrachial nuclei of the pons (Reiner and Vincent, 1987; Vincent and Reiner, 1987). ChAT-immunoreactive neurons were also observable in the parabigeminal and oculomotor nuclei.

\section{Distribution of double-labeled neurons detected by FGAh}

FG injections into both SN and VTA resulted in detectable retrograde transport to ChAT-positive cells throughout the LDTgPPTg complex. The pattern of this distribution of FG-ChAT double-labeled cells varied depending on which dopaminergic area was injected. This difference was most apparent on the side ipsilateral to the injections, maps of which are displayed in Figure 2. Examples of both ChAT-positive and retrogradely labeled cells can be seen in Figure 3.

In VTA-injected cases, the distribution of projecting cholinergic cells tended to be proportional to the distribution of the cholinergic cells, with most VTA-projecting cholinergic cells originating from the areas where ChAT-positive cells are most numerous, in the LDTg and PPTg pars compacta. The VTAprojecting cholinergic cells were also nearly equally distributed bilaterally.

In the SN-injected cases, approximately two-thirds of the cholinergic projection to $\mathrm{SN}$ originated on the ipsilateral side, particularly from areas in the PPTg. Cholinergic cells projecting to $\mathrm{SN}$ are distributed throughout the entire area containing cholinergic cells, but not proportionally to the distribution of cholinergic cells. The denser areas of SN-projecting ChAT neurons were found in two areas where ChAT cells are relatively less denscly distributed: in the rostroventral PPTg, and in medial regions of the PPTg ventral to the mlf and medial to the scp at more caudal levels (PPTg ventral part in Woolf and Butcher, 1986). SN-projecting cholinergic neurons are also much less prevalent in the LDTg than are VTA-projecting cholinergic neurons.

While the major differences between the two distributions are readily apparent on the ipsilateral side, results on the sides contralateral to the injections were approximately similar regardless of whether SN or VTA was injected, although relatively fewer $\mathrm{SN}$-projecting cholinergic cells are found contralaterally.

The differences between the two distributions are particularly apparent when the densities of the two projections are plotted and compared to the distribution of the ChAT cells (Fig. 4). The highest density of VTA-projecting cholinergic cells is clearly coincident with the areas of highest cholinergic cell density within the LDTg and PPTg. The density of this projection is approximately equal both ipsi- and contralateral to the injection. There is also a noticeable tendency for VTA-projecting cholinergic cells in the PPTg to originate from more dorsal, and hence more caudal, aspects of that nucleus. In contrast, the highest densities of SN-projecting cells are found ipsilateral to the injection sites in areas where the ChAT cells as a whole are relatively less densely distributed, particularly in areas of the ventrolateral and dorsomedial PPTg. The paucity of SN-projecting cholinergic cells in the LDTg is also notable. Subtracting the density values for SN-projecting cells from those for VTA-projecting cells reveals distinct areas within the cholinergic group where one of the two projections predominates (Fig. 4C). For VTA, these areas include the core of the LDTg and dorsocaudal aspects of the PPTg compacta, whereas for the SN they include regions of the ipsilateral PPTg dissipata ventral to the mlf and medial to the SCP, and ventrolateral aspects of the PPTg's rostral pole.

Statistical comparisons of the cell distributions using hierarchical log-linear analysis confirm these observations. On the ipsilateral sides, the partial likelihood-ratio chi square is found to be significant $(p<0.05)$ for all three axes $\left(\mathrm{X}: \mathrm{pL}^{2}=30.939\right.$, $\mathrm{df}=12, p=0.002 ; \mathrm{Y}: \mathrm{pL}^{2}=27.303, \mathrm{df}=12, p=0.007 ; \mathrm{Z}$ : $\mathrm{pL}^{2}=10.557, \mathrm{df}=4, p=0.032$ ), demonstrating that the differences between the double-labeled cell distributions are significant above and beyond any of the underlying effects, including variations in the underlying distribution of ChAT cells between groups. Contralaterally, the distributions are found to differ significantly only on the $\mathrm{Z}$ axis $\left(\mathrm{pL}^{2}=16.407\right.$, df $=4, p$ $=0.0025$ ), reflecting a tendency of the VTA projection to originate from more caudal regions.

Partial likelihood-ratio chi square also provides statistical confirmation of the differences in how the two projections are organized relative to the cholinergic group as a whole. The distri- 


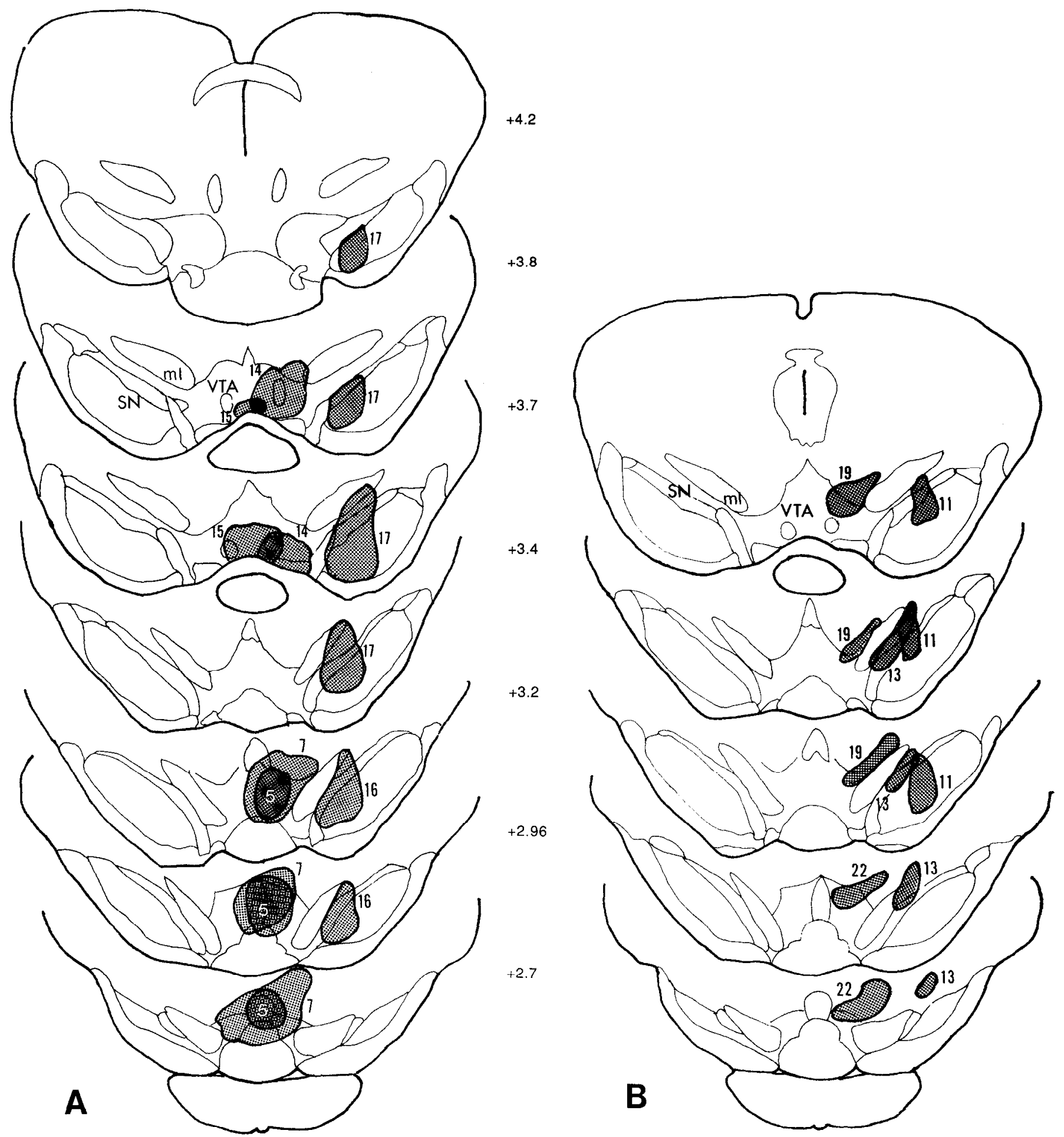

Figure 1. Extent of retrograde tracer injections. A, Fluoro-Gold injections. B, Rhodamine latex microsphere injections. Numerals denote case numbers of animals meeting criteria for inclusion in this study. Injection locations relative to actual locations of dopaminergic cells were confirmed by comparison to control sections immunohistochemically stained for tyrosine hydroxylase. Section outlines redrawn from the atlas of Paxinos and Watson (1986); anterior-posterior levels given in millimeters relative to interaural zero. $m l$, medial lemniscus; $S N$, substantia nigra; VTA, ventral tegmental area.

butions of projecting cholinergic cells in the SN-injected group are found to differ significantly from single-labeled ChAT cells on each axis on the ipsilateral side $\left(\mathrm{X}: \mathrm{pL}^{2}=25.513, \mathrm{df}=11\right.$, $p=0.0077 ; \mathrm{Y}: \mathrm{pL}^{2}=39.533$, df $=12, p=0.0001 ; \mathrm{Z}: \mathrm{pL}^{2}=$ 10.67 , df $=4, p=0.0305$ ), but not on the contralateral side.
Results for the VTA-projecting cholinergic cells indicate no difference between their distribution and that of single-labeled ChAT cells on the dorsoventral (Y) axis, contralateral mediolateral $(\mathrm{X})$ axis, and ipsilateral rostrocaudal (Z) axis, suggesting that the overall pattern of the cholinergic projection to VTA is 

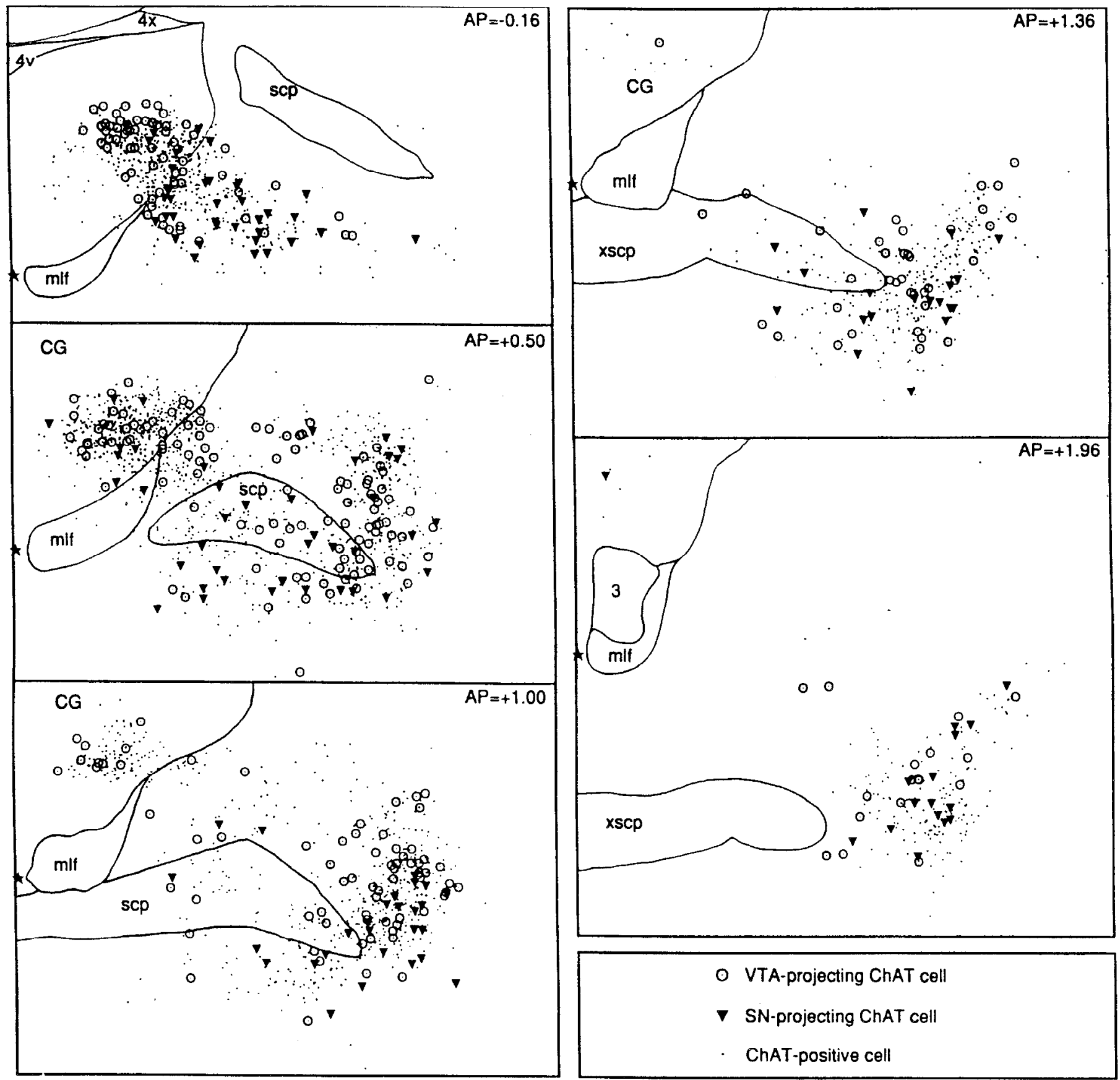

Figure 2. Actual locations of cholinergic and projecting cholinergic cells mapped in five anatomical planes. All ChAT-positive cells ipsilateral to injection sites in the six cases analyzed by the hierarchical log-linear method (four VTA injections, two SN) are plotted. Hierarchical log-linear analysis demonstrated that the distribution of projecting cholinergic cells in $\mathrm{SN}$-injected animals was significantly different from that observed either for VTA-projecting cholinergic cells or for nonprojecting ChAT-positive cells. The distribution of VTA-projecting ChAT cells is not significantly different from the ChAT cells as a whole. Outlines of anatomical landmarks redrawn from corresponding figures in Paxinos and Watson (1986). Anterior-posterior levels given in millimeters relative to interaural zero. 3 , oculomotor nucleus; $4 v$, fourth ventricle; $4 x$, decussation of trochlear nerve; $C G$, central gray; $m l f$, medial longitudinal fasciculus; $s c p$, superior cerebellar peduncle; $x s c p$, decussation of scp.

distributed proportionally to the ChAT cells. Significant differences noted on the ipsilateral $\mathrm{X}$ axis $\left(\mathrm{pL}^{2}=23.024, \mathrm{df}=11, p\right.$ $=0.0175)$ and contralateral $\mathrm{Z}$ axis $\left(\mathrm{pL}^{2}=16.672, \mathrm{df}=4, p=\right.$ 0.0022 ) may reflect a slightly more medial location of the highest density of VTA-projecting cells relative to ChAT cells in the ipsilateral LDTg and the tendency for VTA-projecting cells on the contralatcral side to originate from more caudal aspects of the nucleus.

\section{Comparison of tracers and detection methods}

The overall pattern of retrograde transport observed was similar when rhodamine-labeled latex microspheres (RLM) were used or when FG was detected without immunohistochemical enhancement. RLM injections to SN resulted in a predominately ipsilatcral pattern of retrogradely labelcd cholincrgic neurons, concentrated in ventrolateral areas of the rostral PPTg. A con- 

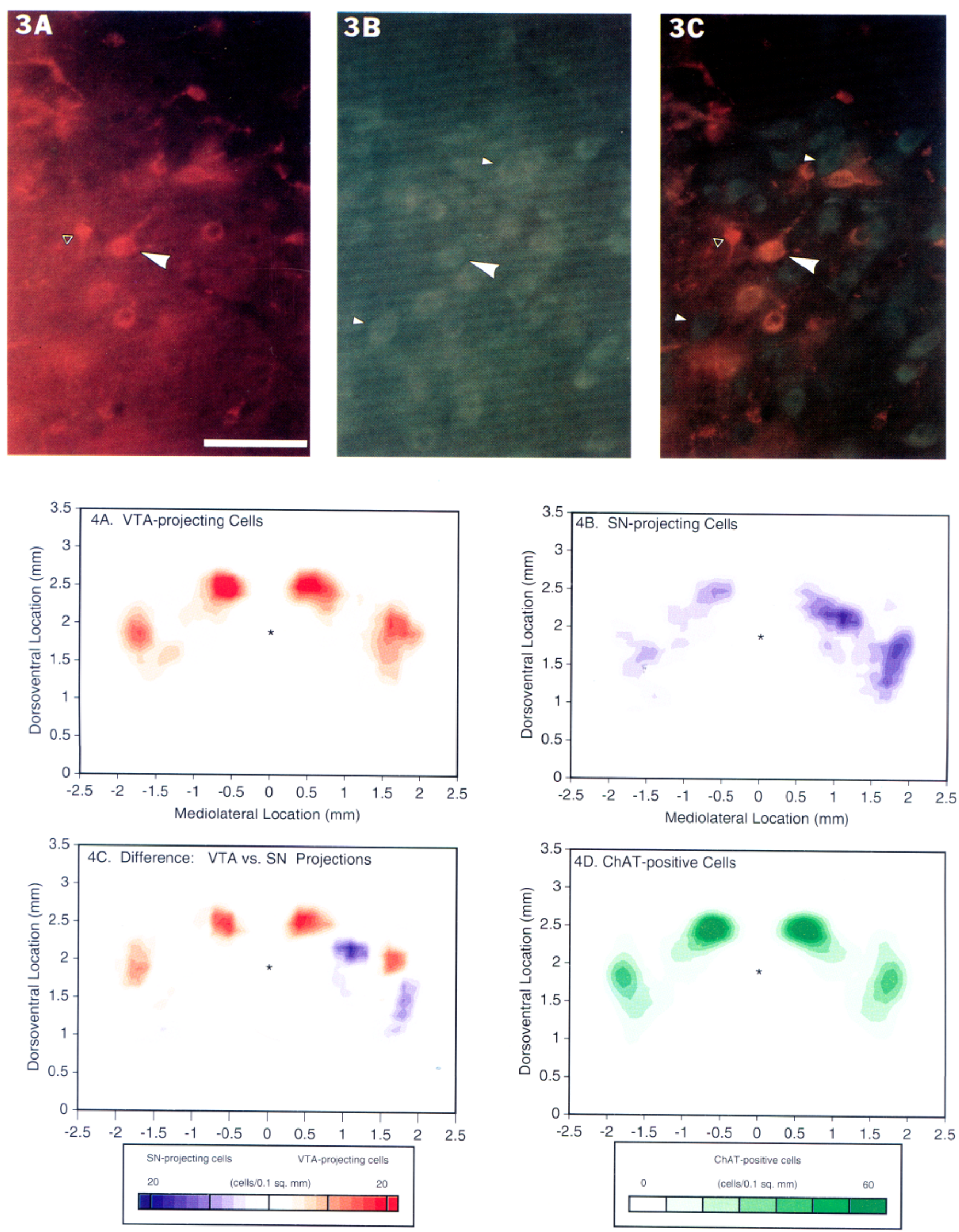

Figure 3 (Top). Representative labeled cells seen in laterodorsal tegmental nucleus of an animal with a Fluoro-Gold (FG) injection to the VTA. $A$, Retrogradely labeled cells in which the FG has been amplified by an immunohistochemical method and labeled with Texas red. $B$, ChATimmunoreactive cells in the same field, labeled with FITC. $C$. Double exposure showing both labels in the same field. Large arrowhead points to a representative double-labeled cell visible in each panel. Small solid arrowheads indicate single-labeled ChAT-positive cells in $B$ and $C$, while open arrowhead in $A$ and $C$ denotes a representative single-labeled cell containing the retrograde label. Scale bar in $A=100 \mu \mathrm{m}$. 
centration of retrogradely labeled cholinergic cells could also be observed in caudal regions of the ipsilateral PPTg dissipata ventral to the mlf and medial to the SCP, the same area where SNprojecting concentrations were observed in FG-injected cases. RLM injections to portions of VTA resulted in substantially less labeling of cholinergic cells (a total of 11 cells in two cases), possibly a function of the small areas of VTA infused with this traccr. Thesc double-labeled cells were found bilaterally in the LDTg, and at the dorsocaudal pole of the ipsilateral PPTg compacta.

The immunohistochemical enhancement of FG resulted in, on average, a sixfold increase in the number of double-labeled cells detected, compared to the visualization of FG alone in adjacent sections from the same cases. In the VTA cases, use of the antiFG antibody to amplify and detect the tracer did not result in a substantially different pattern of retrograde transport when compared to the visualization of FG alone. The pattern of FG-labeled cholinergic cells observed in SN cases appeared somewhat more widely scattered within the cholinergic group, when compared to adjacent sections mapped using the anti-FG method. Nevertheless, the majority of ipsilateral SN-projecting cholinergic neurons was still found within the ventrolateral rostral PPTg and the mediocaudal area previously noted.

\section{Cell area and shape data}

The mean cross-sectional areas of all ChAT-positive cells differed by $6.4 \%$ between the two groups (VTA: $204 \mu \mathrm{m}^{2}$; SN: $217 \mu \mathrm{m}^{2}$; Table 1). This amounts to an average variation of only $1.5 \%$ in linear dimensions, most likely due to small individual variabilities in the normal $20 \%$ shrinkage of the brain due to tissue fixation. To normalize groups for fixation-related variabilities, all cells in each group were ranked on the basis of their mcasured cross-sectional areas and the percentage of projecting cells plotted as a function of the area decile to which they belong (Fig. 5A). Cholinergic cells which project to either dopaminergic nucleus are more likely to be found in the deciles containing the larger cholinergic cells. In each group, this nonuniform distribution of projecting cells was found to be significantly different from the more uniform distribution of nonprojecting cells (VTA: $\chi^{2}=53.77$, df $=9, p<0.0001 ; \chi^{2}=53.73$, df $=9, p<$ $0.0001)$. Neither single- nor double-labeled cells were found to distribute differently between groups on this test (projecting cells: $\chi^{2}=14.12$, df $=9, p=0.118$; nonprojecting cells: $\chi^{2}=$ 1.54 , $\mathrm{df}=9, p=0.997$ ). Projecting cells from the two groups were also compared together against thalamic-projecting cholinergic cells observed in a case in which a large FG injection filled the anterior half of the thalamus. A significant difference was found between these area distributions $\left(\chi^{2}=21.08, \mathrm{df}=9, p\right.$ $=0.012$ ), suggesting the possibility that a particular subpopulation of smaller cholinergic cells may project to SN or VTA independently of those projecting to the thalamus.

Shape factors (Table 1) are a measure of the circularity of each cell's outline. The formula used, $4 \pi *$ area/(perimeter $)^{2}$,
Table 1. Cell areas and shape factors

\begin{tabular}{|c|c|c|c|}
\hline Cell type & $N$ & $\begin{array}{l}\text { Cross-sectional } \\
\text { area }\left(\mu \mathrm{m}^{2} ;\right. \\
\text { Mean } \pm \text { SEM })\end{array}$ & $\begin{array}{l}\text { Shape factor } \\
(\text { Mean } \pm \text { SEM) }\end{array}$ \\
\hline $\begin{array}{l}\text { Nonprojecting ChAT } \\
\text { positive (4 VTA cases) }\end{array}$ & 3114 & $206.0 \pm 1.1$ & $0.867 \pm 0.0015$ \\
\hline VTA-projecting & & & \\
\hline ChAT positive & 586 & $222.5 \pm 2.3$ & $0.873 \pm 0.0033$ \\
\hline $\begin{array}{l}\text { Nonprojecting ChAT } \\
\text { positive ( } 2 \mathrm{SN} \text { cases) }\end{array}$ & 1592 & $205.1 \pm 1.4$ & $0.867 \pm 0.0022$ \\
\hline SN-projecting & & & \\
\hline ChAT positive & 220 & $229.2 \pm 3.3$ & $0.870 \pm 0.0060$ \\
\hline Total & 5512 & $208.4 \pm 0.8$ & $0.869 \pm 0.0012$ \\
\hline
\end{tabular}

returns values between 1.0 , for a circle, and 0.0 , for a line, and as such is not influenced by fixation-related shrinkage. Mean shape factors were not found to differ significantly between any groups of cells (Kruskal-Wallis one-way ANOVA, $\chi^{2}=3.19$, $\mathrm{df}=3, p=0.363$ ).

\section{Discussion}

Our findings demonstrate that populations of cholinergic neurons projecting to SN or VTA differ significantly according to their locations within the pontomesencephalic cholinergic group. These differences strongly suggest that this cholinergic group is internally organized to dissociate its innervation of functionally divergent targets.

We observe an extensive bilateral cholinergic innervation of the VTA, originating primarily in the LDTg and caudal PPTg, where cholinergic cells are more densely concentrated. This projection has not been thoroughly described in the literature, although Woolf and Butcher (1985) reported substantial retrograde transport to the LDTg from VTA injections made as controls to interpeduncular nucleus injections, and Bolton et al. (1993) report cholinergic innervation of VTA by collaterals of LDTg neurons projecting to midline thalamic nuclei. Sugimoto and Hattori (1984) and Cornwall et al. (1990) also report innervation of VTA by neurons in PPTg and LDTg, respectively, although these were not directly identified as cholinergic.

We also observe a cholinergic projection to $\mathrm{SN}$ which is primarily ipsilateral, originating in less dense regions of the cholinergic group. Current evidence strongly supports the existence of a cholinergic PPTg/LDTg projection to SN (Woolf and Butcher, 1986; Beninato and Spencer, 1987; Clarke et al., 1987; Gould et al., 1989; Martinez-Murillo et al., 1989; Bolam et al., 1991). Controversy about a cholinergic PPTg projection to SN seems based primarily on disagreement over whether to define the PPTg cytoarchitecturally, as it was originally defined in the human brainstem (Olszewski and Baxter, 1954), neurochemically (Mesulam et al., 1983), or hodologically (Rye et al., 1987; Lee

$\leftarrow$

Figure 4 (Bottom). Densities of SN- and VTA-projecting cholinergic cells within the pontomesencephalic group. Plots each include data from all five mapped planes, aligned relative to the position of the mlf and collapsed onto a single plane. Star indicates position of inter-mlf landmark. A, Cholinergic cells projecting to ventral tegmental area $(V T A)$. The areas of highest density for this projection correspond well with the highest densities of cholinergic group as a whole $(D)$. B. Cholinergic cells projecting to substantia nigra $(S N)$. Note ventromedial concentration of cells on right (ipsilateral) side. C. Difference in density distributions of VTA- and SN-projecting cholinergic cells. Cells in blue areas project predominantly to SN, red to VTA. $D$, Density distribution for all ChAT-positive cells in pontomesencephalic group. Density scale has been reduced relative to other plots for sake of clarity. 

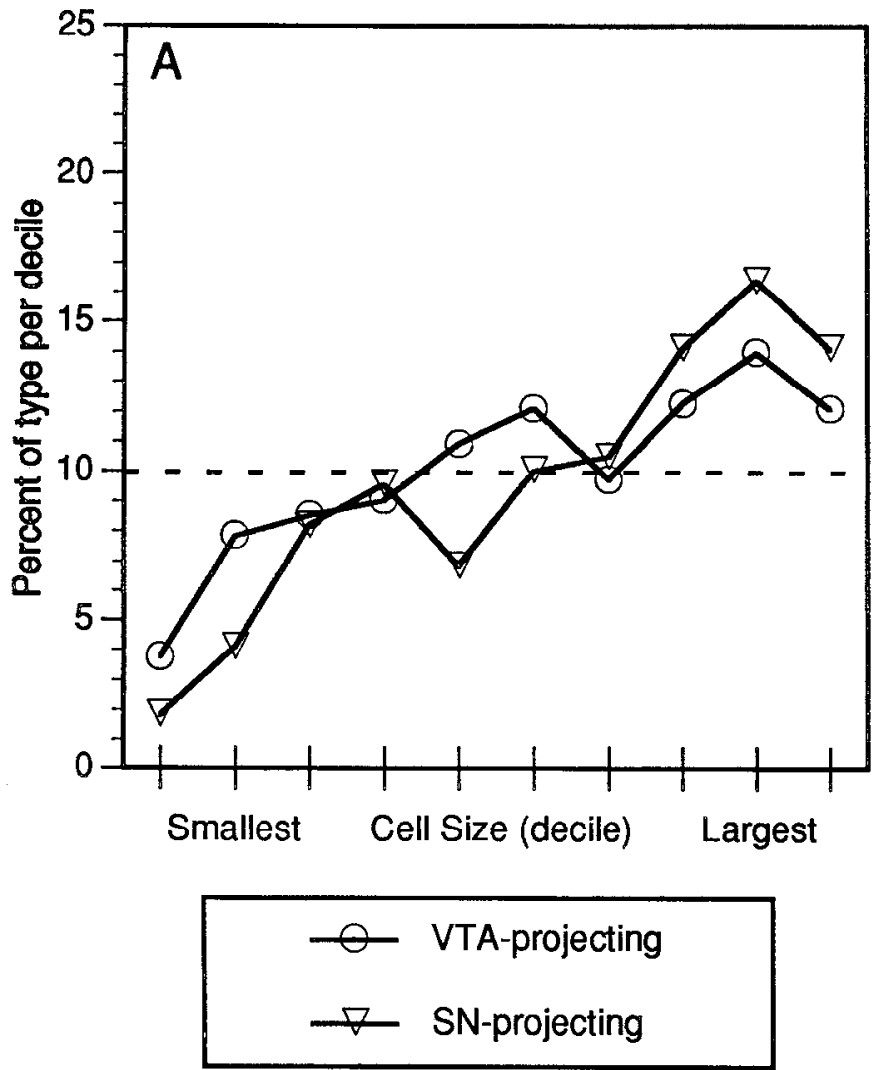

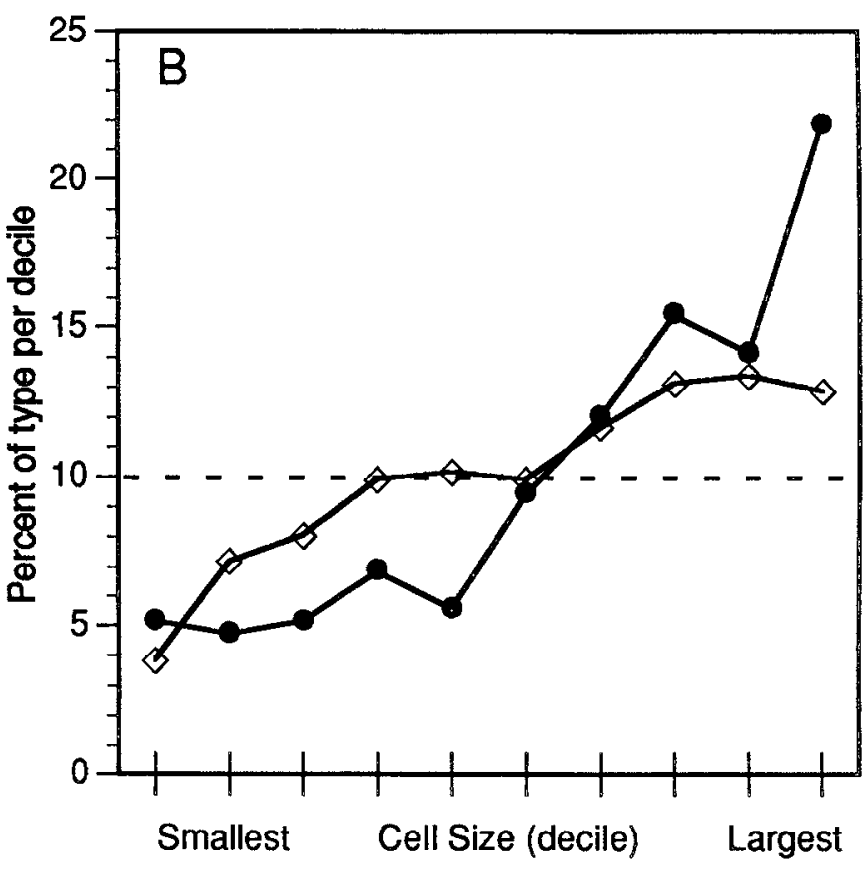

$\neg$ SN- or VTA-projecting

$\rightarrow$ Thalamus-projecting

Figure 5. Distribution of cell areas normalized by decile rank. Projecting cholinergic cells are distributed nonuniformly across the deciles of cell cross-sectional area. Dashed line indicates uniform distribution. A, Distribution of SN- and VTA-projecting cells by ranked cross-sectional area. Cells projecting to either SN or VTA are more likely to be found among the larger cells in the PPTg and LDTg. The distributions for SN- and VTA-projecting neurons do not differ significantly from each other. $B$, Area distributions of SN- or VTA-projecting cholinergic neurons versus thalamus-projecting cholinergic neurons. Thalamus-projecting neurons are significantly more likely to be of the larger cells in the distribution ( $p$ $=0.012$ ).

et al., 1988; Steininger et al., 1992). The latter approach, based on the examination of reciprocal connections between tegmental regions and the extrapyramidal motor system, has caused some to make a distinction between the PPTg and an area defined as the midbrain extrapyramidal area (MEA). We, however, consistently observe a population of large cholinergic cells within the area defined as MEA, an area which also corresponds to the medial PPTg dissipatus (as defined cytoarchitectonically), and which is also referred to as the PPTg, ventral part (Woolf and Butcher, 1986), or subpeduncular tegmental nucleus (SPTg, Paxinos and Watson, 1986) in rat. This area is, in fact, the area where we observe the highest densities of cholinergic cells which project to SN, and appears to correspond at least partially to the area described as MEA and to the area in which Spann and Grofova $(1989,1991,1992)$ and Hall et al. (1989) report dense terminal fields of nigrotegmental fibers.

\section{Statistical analysis}

We are able to ascribe a high level of statistical confidence to this observed difference in cell distributions. With careful visual analysis of Figure 2, one can observe the patterns of cell distribution described above. However, in the absence of a suitable statistical evaluation of the data, it is not possible to be certain whether this degree of clustering might not frequently be observed on the basis of chance alone. The discipline of neuroanatomy is becoming increasingly more concerned with distinguishing subtle differences in the organization of complex cell groups, many of which contain diverse subpopulations defined with respect to hodology, neurochemical and physiological characteristics, or morphometric criteria. It is helpful to have tools which can describe these observed differences according to quantitative, objective criteria. As the use of computer-aided digital mapping equipment now makes the acquisition of precise structural and locational data routine, it is also necessary to develop suitable statistical analyses for this data.

A difficulty one encounters in attempting to statistically discriminate neuronal subpopulations measured in this way, particularly when one is comparing data across different individual cases, is that slight differences in the parent populations from which the subpopulations are drawn may be interpreted as statistically significant. Statistically significant differences between subpopulations are then rendered indistinguishable from those due to this underlying covariance. The hierarchical nature of the log-linear analysis used allows one to determine statistically the degree to which observed anatomical differences in cell distributions are significant over and above significant differences between their parent populations, thus allowing one to statistically discriminate subpopulations within large neuronal populations which contain significant covariance.

\section{Functional topography and control of behavioral state}

The functional dissociation we observe between SN- and VTAprojecting cholinergic neurons is consistent with the functional topographies previously proposed for this group, based on stud- 
ies of its efferents to thalamic nuclei (Woolf and Butcher, 1986, 1989; Hallanger et al., 1987). These "functional zones," however, cannot be said to be exclusive, as cells projecting to either dopaminergic nucleus can be found throughout the cholinergic group, on both ipsi- and contralateral sides.

Functional organization fits the data for this system better than alternative possibilities based on spatial location or neurochemical characteristics of the targets. If the organization of the cholinergic complex reflected only the differing spatial locations of the targets, one would expect to see, for example, medial portions of the cholinergic group predominating in innervation of medial targets, and lateral portions projecting to lateral targets. Although the medial dopamine system (VTA) does receive a substantial projection from the medial cholinergic group (LDTg) and the lateral target (SN) from lateral aspects of the complex, our data also displays numerous exceptions to such a scheme, particularly the medially located SN projecting neurons observed. In addition, as collateralization studies have shown that individual cholinergic neurons may have both ascending and descending projections (Jourdain et al., 1989; Spann and Grofova, 1989; Woolf and Butcher, 1989; Higo et al., 1990; Semba et al., 1990), it is unlikely that the system is organized simply by segregating ascending from descending projection neurons. Finally, since it is reported that single cholinergic neurons also may innervate both thalamic and monoaminergic targets (Bolton et a1., 1993), it is unlikely that the cholinergic complex is organized simply along neurochemical lines.

Unlike the familiar somatotopic organization found in sensory and motor control systems, the LDTg/PPTg complex displays the widespread, diffuse innervation of the CNS which is typical of monoaminergic systems which modulate behavioral state and responsivity (Woolf and Butcher, 1986, 1989; Rye et al., 1988; Hall et al., 1989; Cornwall et al., 1990; Jones, 1990; Bolton et al., 1993; Losier and Semba, 1993). Functional topography implies that cholinergic outflow to functionally different systems will vary depending on where within the cholinergic group afferent input is received. Afferents to both LDTg and PPTg have been demonstrated from brainstem and forebrain regions associated with a wide variety of limbic, visceral, and sensorimotor functions (Satoh and Fibiger, 1986; Cornwall et al., 1990; Semba and Fibiger, 1992; Steininger et al., 1992). Based on our data, input to the dense cores of the group appears more likely to affect cholinergic outflow to the mesolimbic dopamine system than to the nigrostriatal system. However, its probability of influencing the nigrostriatal system is not zero, since some SNprojecting cells are found throughout the areas containing cholinergic cells. Our findings also imply that input received by an SN-projecting cell is more likely to affect the ipsilateral nigrostriatal system than to be relayed to the contralateral side. The VTA, however, a midline structure, appears likely to receive cholinergic input from either side of the cholinergic group.

\section{Importance of functional organization in the brainstem cholinergic system}

We believe that our identification of a distinct difference in how the cholincrgic inncrvation of SN and VTA is organized within the LDTg/PPTg provides important information about how this cholinergic system regulates CNS systems which control hehavioral state. Since Shute and Lewis (1967) identified the cholinergic component of the ascending reticular activating system with the LDTg and PPTg, involvement of this system in general arousal functions has been extensively studied (see Steriade and
Buzsaki, 1990). A systcm controlling this function needs to be able to integrate incoming information from several sources and to direct responses by regulating levels of activity in many neural circuits. The anatomical characteristics of the pontomesencephalic cholinergic system are consistent with the requirements of such a system.

Given the important role played by biogenic amines in modulation of behavioral state through their widespread innervation and neuromodulatory action in many neural systems (Reiner, 1986; Jones, 1991a), it seems reasonable to us that a neural system controlling behavioral state would also need to influence central monoaminergic activity. We suggest that an important role of the pontomesencephalic cholinergic system may include regulating monoaminergic tone in other brain regions via demonstrated anatomical connections to the raphe nuclei, locus coeruleus, and dopamine systems (Hartman et al., 1988; Woolf and Butcher, 1989). Physiological and bchavioral cvidence provides additional support for this hypothesis. Several studies have demonstrated the existence of nicotinic and muscarinic receptors in SN and VTA (Clarke et al., 1985; Deutch et al., 1987; Swanson et al., 1987; Vilaro et al., 1990; Wada et al., 1990; Weiner et al., 1990; Nastuk and Graybiel, 1991) and the effects of cholinergic agents on catecholaminergic neurons (Egan and North, 1986; Clarke el al., 1987; Niijima and Yoshida, 1988; Calbresi et al., 1989; Lacey et al., 1990; Blaha and Winn, 1993).

Interactions between midbrain cholinergic and monoaminergic cell populations are likely to have relevance to topics as diverse as control of sleep states (Hobson et al., 1975; Reiner and Vincent, 1987; Jones, 1991b; Leubke et al., 1992; Williams and Reiner, 1993), Parkinsonism (McGeer and McGeer, 1984; Jellinger, 1991), schizophrenia (Tandon and Greden, 1989; Karson et al., 1991, 1993; Tandon et al., 1991), and psychotropic drug effects. Future research will illuminate whether cholinergic efferents to other monoaminergic groups are organized according to the same functional scheme we demonstrate for the major dopaminergic groups. We believe that the quantitative, statistical analysis of anatomical data presented here can serve as a useful tool for future investigations of cell populations containing heterogeneous morphological, hodological, or neurochemical subtypes.

\section{References}

Beninato M, Spencer RF (1987) A cholinergic projection to the rat substantia nigra from the pedunculopontine tegmental nucleus. Brain Res 412:169-174.

Berod A, Hartman BK, Keller A, Joh TH, Pujol JF (1981) A new double labeling technique using TH and DBH immunohistochemistry: evidence for dopaminergic cells lying in the pons of the beef brain. Brain Res 240:235-243.

Blaha CD, Winn P (1993) Modulation of dopamine efflux in the striatum following cholinergic stimulation of the substantia nigra in intact and pedunculopontine tegmental nucleus-lesioned rats. J Neurosci 13:1035-1044.

Bolam JP, Francis CM, Henderson Z (1991) Cholinergic input to dopaminergic neurons in the substantia nigra: a double immunocytochemical study. Neuroscience 41:483-494.

Bolton RF, Cornwall J, Phillipson OT (1993) Collateral axons of cholinergic pontine neurons projecting to midline, mediodorsal and parafascicular thalamic nuclei in the rat. J Chem Neuroanat 6:101-114.

Calabresi P, Lacey MG, North RA (1989) Nicotinic excitation of rat ventral tegmental neurones in vitro studied by intracellular recording. Br J Pharmacol 98:135-140.

Chang HT, Kuo H, Whittaker JA, Cooper NGF (1990) Light and electron microscopic analysis of projection neurons retrogradely labeled with Fluoro-Gold: notes on the application of antibodies to FluoroGold. J Neurosci Methods 35:31-37. 
Clarke PB, Schwartz RD, Paul SM, Pert CB, Pcrt A (1985) Nicotinic binding in rat brain: autoradiographic comparison of $\left[{ }^{3} \mathrm{H}\right]$ acetylcholine, $\left[{ }^{3} \mathrm{H}\right]$ nicotine, and $\left[{ }^{125} \mathrm{I}\right]$-alpha-bungarotoxin. J Neurosci 5:13071315.

Clarke PB, Hommer DW, Pert A, Skirboll LR (1987) Innervation of substantia nigra neurons by cholinergic afferents from pedunculopontine nucleus in the rat: neuroanatomical and electrophysiological evidence. Neuroscience 23:1011-1019.

Cornwall J, Cooper JD, Phillipson OT (1990) Afferent and efferent connections of the laterodorsal tegmental nucleus in the rat. Brain Res Bull 25:271-284.

Cozzari C, Howard J, Hartman BK (1990) Analysis of epitopes on choline acetyltransferase (ChAT) using monoclonal antibodies (mabs). Neurosci Abstr 16:200.

Deutch AY, Holliday J, Roth RH, Chun LLY, Hawrot E (1987) Immunohistochemical localization of a neuronal nicotinic acetylcholine receptor in mammalian brain. Proc Natl Acad Sci USA 84:86978701.

Egan TM, North RA (1986) Actions of acetylcholine and nicotine on rat locus coeruleus neurons in vitro. Neuroscience 19:565-571.

Fox J (1984) Linear statistical models and related methods with applications to social research, pp 336-347. New York: Wiley.

Gould E, Woolf NJ, Butcher LL (1989) Cholinergic projections to the substantia nigra from the pedunculopontine and laterodorsal tegmental nuclei. Neuroscience 28:611-623.

Hall WC, Fitzpatrick D, Klatt LL, Raczowski D (1989) Cholinergic innervation of the superior colliculus in the cat. J Comp Neurol 287: $495-514$.

Hallanger AE, Wainer $\mathrm{BH}$ (1988) Ascending projections from the pedunculopontine tegmental nucleus and the adjacent mesopontine tegmentum in the rat. J Comp Neurol 274:483-515.

Hallanger AE, Levey AI, Lee HJ, Rye DB, Wainer BH (1987) The origins of cholinergic and other subcortical afferents to the thalamus in the rat. $J$ Comp Neurol 262:105-124.

Hartman BK, Faris PL, Kalmbach SJ, Cozzari C, Berod A (1988) Central cholinergic innervation of the dopaminergic and serotonergic systems. Soc Neurosei Abstr 14:1213.

Henderson Z, Sherriff FE (1991) Distribution of choline acetyltransferase immunoreactive axons and terminals in the rat and ferret brainstem. J Comp Neurol 314:147-163.

Higo S, Ito K, Fuchs D, McCarley RW (1990) Anatomical interconnections of the pedunculopontine tegmental nucleus and the nucleus prepositus hypoglossi in the cat. Brain Res 536:79-85.

Hobson JA, McCarley RW, Wyzinski PW (1975) Sleep cycle oscillation: reciprocal discharge by two brainstem neuronal groups. Science 189:55-58.

Jellinger KA (1991) Pathology of Parkinson's Disease. Changes other than the nigrostriatal pathway. Mol Chem Neuropathol 14:153-197.

Jones BE (1990) Immunohistochemical study of choline acetyltransferase-immunoreactive processes and cells innervating the pontomedullary reticular formation in the rat. J Comp Neurol 295:485514.

Jones BE (1991a) Noradrenergic locus coeruleus neurons: their distant connections and their relationship to neighboring (including cholinergic and GABAergic) neurons of the central gray and reticular formation. In: Progress in brain research (Barnes CD, Pompeiano O, eds), pp 15-30. Amsterdam: Elsevier.

Jones BE (1991b) The role of noradrenergic locus coeruleus neurons and neighboring cholinergic neurons of the pontomesencephalic tegmentum in sleep-wake states. In: Progress in brain research (Barnes CD, Pompeiano O, eds), pp 533-543. Amsterdam: Elsevier.

Jourdain A, Semba K, Fibiger IIC (1989) Basal forebrain and mesopontine tegmental projections to the reticular thalamic nucleus: an axonal collateralization and immunohistochemical study in the rat. Brain Res 505:55-65.

Karson CN, Garcia-Rill E, Biedermann J, Mrak RE, Husain MM, Skinner RD (1991) The brain stem reticular formation in schizophrenia. Psychol Res: Neuroimaging 40:31-48.

Karson CN, Casanova MF, Kleinmann JE, Griffin WST (1993) Choline acetyltransferase in schizophrenia. Am .I Psychiatry 150:454-459.

Lacey MG, Calabresi P, North RA (1990) Muscarine depolarizes rat substantia nigra zona compacta and ventral tegmental neurons in vitro through M1-like receptors. J Pharmacol Exp Ther 253:395 400.

Lee HJ, Rye DB, Hallanger AE, Levey AI, Wainer BH (1988) Cholinergic vs. noncholinergic efferents from the mesopontine tegmentum to the extrapyramidal motor system nuclei. J Comp Neurol 275:469492.

Leubke JI, Greene RW, Semba K, Kamondi A, McCarley RW, Reiner PB (1992) Serotonin hyperpolarizes cholinergic low-threshold burst neurons in the rat laterodorsal tegmental nucleus in vitro. Proc Natl Acad Sci USA 89:743-747.

Losier BJ, Semba K (1993) Dual projections of single cholinergic and aminergic brainstem neurons to the thalamus and basal forebrain in the rat. Brain Res 604:41-52.

Martinez-Murillo R, Villalba RM, Rodrigo J (1989) Electron microscopic localization of cholinergic terminals in the rat substantia nigra: an immunocytochemical study. Neurosci Lett 96:121-126.

McGeer EG, McGeer PL (1984) Substantia nigra cell death from kainic acid or folic acid injections into the pontine tegmentum. Brain Res. 298:339-342.

Mesulam M-M, Mufson EJ, Wainer BH, Levey AI (1983) Central cholinergic pathways in the rat: an overview based on an alternative nomenclature (Ch1-Ch6). Neuroscience 10:1185-1201.

Nastuk MA, Graybiel AM (1991) Pharmacologically defined M1 and M2 muscarinic cholinergic binding sites in the cat's substantia nigra: development and maturity. Dev Brain Res 61:1-10.

Niijima K, Yoshida M (1988) Activation of mesencephalic dopamine neurons by chemical stimulation of the nucleus tegmenti pedunculopontinus pars compacta. Brain Res 451:163-171.

Norusis MJ (1990) SPSS advanced statistics user's guide, pp 151-172. Chicago: SPSS Inc.

Olszewski J, Baxter D (1954) Cytoarchitecture of the human brainstem, p 195. Philadelphia: J.B. Lippincott.

Paxinos G, Watson C (1986) The rat brain in stereotaxic coordinates, second edition. Orlando, FL: Academic.

Reiner PB (1986) Correlational analysis of central noradrenergic neuronal activity and sympathetic tone in behaving cats. Brain Res 378: 86-96.

Reiner PB, Vincent SR (1987) Topographic relations of cholinergic and noradrenergic neurons in the feline pontomesencephalic tegmentum: an immunohistochemical study. Brain Res Bull 19:705-714.

Rye DB, Saper CB, Lee HJ, Wainer BH (1987) Pedunculopontine tegmental nucleus of the rat: cytoarchitecture, cytochemistry, and some extrapyramidal connections of the mesopontine tegmentum. J Comp Neurol 259:483-528.

Rye DB, Lee HJ, Saper CB, Wainer BH (1988) Medullary and spinal efferents of the pedunculopontine tegmental nucleus and adjacent mesopontine tegmentum in the rat. J Comp Neurol 269:315-341.

Satoh K, Fibiger HC (1986) Cholinergic neurons of the laterodorsal tegmental nucleus: efferent and afferent connections. J Comp Neurol 253:277-302.

Saxena S, Hartman BK (1989) Topographical organization of the cholinergic cells projecting from the laterodorsal tegmental (LDTg) and pedunculopontine (PPTg) nuclei to the thalamus in rat brain. Soc Neurosci Abstr 15:229.

Semba K, Fibiger HC (1992) Afferent connections of the laterodorsal and the pedunculopontine tegmental nuclei in the rat: a retro- and antero-grade transport and immunohistochemical study. J Comp Neurol 323:387-410.

Semba K, Reiner PB, McGeer EG, Fibiger HC (1988) Brainstem afferents to the magnocellular basal forebrain studied by axonal transport, immunohistochemistry, and electrophysiology in the rat. $\mathrm{J}$ Comp Neurol 267:433-453.

Semba K, Reiner PR, Fibiger HC. (1990) Single cholinergic mesopontine tegmental neurons project to both the pontine reticular formation and the thalamus in the rat. Neuroscience 38:643-654.

Shutc CCD, Lcwis PR (1967) The ascending cholinergic reticular sys tem: neocortical, olfactory, and subcortical projections. Brain 90: $497-520$.

Spann BM, Grofova I (1989) Origin of ascending and spinal pathways from the nucleus tegmenti pedunculopontinus in the rat. J Comp Neurol 283:13-27.

Spann BM, Grofova I (1991) Nigropedunculopontine projection in the rat: an anterograde tracing study with Phaseolus Vulgaris-Leucoagglutinin (PHA-L). J Comp Neurol 311:375-388.

Spann BM, Grofova I (1992) Cholinergic and non-cholinergic neurons in the rat pedunculopontine tegmental nucleus. Anat Embryol 186: 215227.

Steininger TL, Rye DB, Wainer BH (1992) Afferent projections to the cholinergic pedunculopontine tegmental nucleus and adjacent mid- 
brain extrapyramidal area in the albino rat. I. Retrograde tracing studies. J Comp Neurol 321:515-543.

Steriade M, Buzsaki G (1990) Parallel activation of thalamic and cortical neurons by brainstem and basal forebrain cholinergic systems. In: Brain cholinergic systems (Steriade M, Biesold D, eds), pp 3-62. New York: Oxford UP.

Sugimoto T, Hattori T (1984) Organization and efferent projections of nucleus pedunculopontis pars compacta with special reference to its cholinergic aspects. Neuroscience 11:931-946.

Swanson LW, Simmons DM, Whiting PJ, Lindstrom J (1987) Immunohistochemical localization of neuronal nicotinic receptors in the rodent central nervous system. J Neurosci 7:3334-3342.

Tandon R, Greden JF (1989) Cholinergic hyperactivity and negative schizophrenic symptoms. Arch Gen Psychiatry 46:745-753.

Tandon R, Shipley JE, Greden JF, Mann NA, Eisner WH, Goodson J (1991) Muscarinic cholinergic hyperactivity in schizophrenia: relationship to positive and negative symptoms. Schizophr Res 4:23-30.

Vilaro MT, Palacios JM, Mengod G (1990) Localization of m5 muscarinic receptor mRNA in rat brain examined by in situ hybridization histochemistry. Neurosci Lett 114:154-159.

Vincent SR, Reiner PB (1987) The immunohistochemical localization of choline acetyltransferase in the cat brain. Brain Res Bull 18:371415 .

Wada E, McKinnon D, Heinemann S, Patrick J, Swanson LW (1990) The distribution of mRNA encoded by a new member of the neuronal nicotinic acetylcholine receptor gene family (alpha 5) in the rat central nervous system. Brain Res 526:45-53

Weiner DM, Levey AI, Brann MR (1990) Expression of muscarinic acetylcholine and dopamine receptor mRNAs in rat basal ganglia. Proc Natl Acad Sci USA 87:7050-7054.

Williams JA, Reiner PB (1993) Noradrenaline hyperpolarizes identified rat mesopontine cholinergic neurons in vitro. J Neurosci 13:38783883.

Woolf NJ, Butcher LL (1985) Cholinergic systems in the rat brain: II. Projections to the interpeduncular nucleus. Brain Res Bull 14:63-83.

Woolf NJ, Butcher LL (1986) Cholinergic systems in the rat brain: III. Projections from the pontomesencephalic tegmentum to the thalamus, tectum, basal ganglia, and basal forebrain. Brain Res Bull 16:603637.

Woolf NJ, Butcher LL (1989) Cholinergic systems in the rat brain: IV Descending projections of the pontomesencephalic tegmentum. Brain Res Bull 23:519-540. 